\title{
Long-term management of type 2 diabetes with glucagon-like peptide-I receptor agonists
}

This article was published in the following Dove Press journal:

Diabetes, Metabolic Syndrome and Obesity:Targets and Therapy

13 March 2017

Number of times this article has been viewed

\author{
Hamish Courtney' \\ Rahul Nayar ${ }^{2}$ \\ Chinnadorai Rajeswaran ${ }^{3}$ \\ Ravi Jandhyala ${ }^{4}$ \\ 'Diabetes Department, Royal Victoria \\ Hospital, Belfast, ${ }^{2}$ City Hospitals \\ Sunderland NHS Foundation Trust, \\ Sunderland, ${ }^{3}$ Department of Diabetes \\ \& Endocrinology, Mid Yorkshire NHS \\ Trust, Dewsbury, ${ }^{4}$ Medical Affairs, \\ Diabetes, AstraZeneca, Luton, UK
}

Correspondence: Chinnadorai Rajeswaran Department of Diabetes \& Endocrinology, Mid Yorkshire NHS Trust, Dewsbury Hospital Halifax Road, Dewsbury WFI3 4HS, UK Email chinnadorai.rajeswaran@midyorks. nhs.uk

\begin{abstract}
Continuously reducing excess blood glucose is a primary goal for the management of type 2 diabetes (T2D). Most patients with T2D require glucose-lowering medications to achieve and maintain adequate glycemic control; however, treatment failure may occur, limiting treatment options. Glucagon-like peptide-1 receptor agonists (GLP-1RAs) are an emerging therapeutic class that can be prescribed for patients instead of basal insulin after the failure of oral therapies. Recent studies have focused on the durability and tolerability of long-term GLP1RA therapy. This review summarizes the key efficacy and safety findings from prospective phase 3 clinical studies of at least 76 weeks' duration for the GLP-1RAs currently approved in the United States and the European Union (albiglutide, dulaglutide, exenatide twice daily [BID], exenatide once weekly [QW], liraglutide, and lixisenatide). Currently, most of the long-term data are from uncontrolled extension studies, and continuous patient benefit has been observed for up to 3 years with multiple GLP-1RAs. Four-year comparative data demonstrated a longer time to treatment failure for exenatide BID than for sulfonylurea, and 3-year comparative extension data demonstrated greater glycated hemoglobin $(\mathrm{HbA} 1 \mathrm{c})$ reductions and weight loss with exenatide QW than with insulin glargine. Currently, the longest extension study for a GLP-1RA is the DURATION-1 study of exenatide QW, with $>7$ years of clinical data available. Data from DURATION-1 demonstrated that continuous HbA1c reductions and weight loss were observed for the patients continuing on the treatment, with no unexpected adverse events. Taken together, these data support GLP-1RAs as a long-term noninsulin treatment option after the failure of oral therapies.
\end{abstract}

Keywords: albiglutide, dulaglutide, exenatide, liraglutide, lixisenatide, long-term

\section{Introduction}

Type 2 diabetes (T2D) is a chronic progressive metabolic disease characterized by hyperglycemia and is associated with numerous adverse sequelae, including cardiovascular complications. For many patients with T2D, pharmacological intervention is required to achieve and maintain adequate glycemic control. Given that the severity of the condition typically increases with time, monotherapy (typically with metformin) often fails and additional glucose-lowering medications are needed. ${ }^{1,2}$ Options for the medical treatment of T2D have expanded considerably in recent years. Older glucoselowering medications, including sulfonylureas (SUs), thiazolidinediones (TZDs), and insulin, are now supplemented with newer drug classes comprising dipeptidyl peptidase-4 (DPP-4) inhibitors, glucagon-like peptide-1 receptor agonists (GLP-1RAs), and sodium-glucose cotransporter 2 inhibitors. ${ }^{1,2}$ 
Selecting the most appropriate agent(s) for each patient can be challenging for clinicians. Considerations typically include patient characteristics along with the effectiveness and safety/tolerability profile of the available glucose-lowering therapies. ${ }^{1,2}$ Given the need for lifelong treatment of T2D, prescribers and patients are likely to have more confidence in medications that are supported by long-term efficacy and safety data. Such data not only establish the durability of glycemic control and other clinical benefits but can also potentially identify any important safety and tolerability signals, which may only emerge over an extended duration of observation.

Of the six classes of glucose-lowering medications currently available, the SUs, TZDs, and insulin (by virtue of being the oldest) have accumulated the largest body of long-term efficacy and safety data. In the ADOPT study of patients with recently diagnosed T2D, monotherapy failure rates at 5 years were $21 \%$ with metformin, $15 \%$ with a TZD, and $34 \%$ with an SU. ${ }^{3}$ Despite TZDs holding the best record for durability, fluid retention (potentially leading to heart failure), increased risks of bone fractures, and possible bladder cancer have tempered enthusiasm for this drug class. ${ }^{4}$

GLP-1RAs and DPP-4 inhibitors are incretin-based therapies that mimic and augment, respectively, the action of the incretin hormone glucagon-like peptide-1 (GLP-1). GLP-1RAs are analogs of GLP-1 that mimic GLP-1 and activate the GLP-1 receptor, increasing insulin secretion in a glucose-dependent manner, suppressing glucagon secretion, and delaying gastric emptying, which reduces appetite. ${ }^{5,6}$ GLP-1RAs exploit these mechanisms to control glycemia while simultaneously avoiding hypoglycemia and weight gain. As this is a relatively new class of glucose-lowering agents, unanswered questions remain concerning the longterm use of GLP-1RAs.

This review focuses on the GLP-1RA class, summarizing currently available long-term efficacy and safety data from prospective phase 3 clinical studies of at least 76 weeks' duration. Among the six GLP-1RAs currently approved for use in the United States and the European Union, 19 publications report long-term studies of GLP-1RAs, in some cases compared with other agents or with background oral glucose-lowering therapy (Tables 1 and 2). Findings of recent long-term cardiovascular outcome studies of these GLP-1RAs are also summarized.

\section{Albiglutide once weekly (QW)}

A single study to date has documented the long-term treatment effects of albiglutide (Table 2). HARMONY 3 was a 104-week study comparing the efficacy and safety of albiglutide with sitagliptin, glimepiride, and placebo among patients who have achieved inadequate glycemic control with metformin. ${ }^{7}$ At 2 years, glycated hemoglobin (HbAlc) and weight were reduced by $-0.63 \%$ and $-1.21 \mathrm{~kg}$, respectively, from baseline among patients receiving albiglutide (Table 2).

Key safety and tolerability findings from HARMONY 3 are shown in Table 3. ${ }^{7}$ Two cases of probable pancreatitis, based on laboratory investigations and suggestive symptoms, were considered possibly related to albiglutide. ${ }^{7}$

\section{Dulaglutide QW}

Two studies have assessed the long-term efficacy of dulaglutide (Table 2). AWARD-2 was a 78-week study that compared the efficacy of low- and high-dose dulaglutide ( 0.75 and $1.5 \mathrm{mg}$, respectively) with insulin glargine in patients with T2D not achieving glycemic control with maximum-dose

Table I Currently approved GLP-IRAs and corresponding summary of currently available published data from prospective studies reporting long-term efficacy and safety data

\begin{tabular}{|c|c|c|c|c|c|c|c|c|}
\hline \multirow[t]{2}{*}{ Name } & \multirow[t]{2}{*}{ Marketed name } & \multicolumn{7}{|c|}{$\begin{array}{l}\text { Number of phase } 3 \text { clinical studies reporting efficacy and safety data after a treatment } \\
\text { duration of: }\end{array}$} \\
\hline & & 76-82 weeks & 104 weeks & 156 weeks & 208 weeks & 260 weeks & 312 weeks & 364 weeks \\
\hline Albiglutide QW & $\begin{array}{l}\text { Tanzeum (US), } \\
\text { Eperzan (EU) }\end{array}$ & & 1 & & & & & \\
\hline Dulaglutide QW & Trulicity & 1 & I & & & & & \\
\hline Exenatide BID & Byetta & 3 & & I & 1 & & & \\
\hline Exenatide QW & Bydureon & & I & 2 & & I & I & I \\
\hline Liraglutide QD & Victoza & & 2 & & & & & \\
\hline Lixisenatide QD & $\begin{array}{l}\text { Adlyxin (US), } \\
\text { Lyxumia (EU) }\end{array}$ & 3 & & & & & & \\
\hline
\end{tabular}

Abbreviations: BID, twice daily; EU, European Union; GLP-IRA, glucagon-like peptide-I receptor agonist; QD, once daily; QW, once weekly; US, United States. 


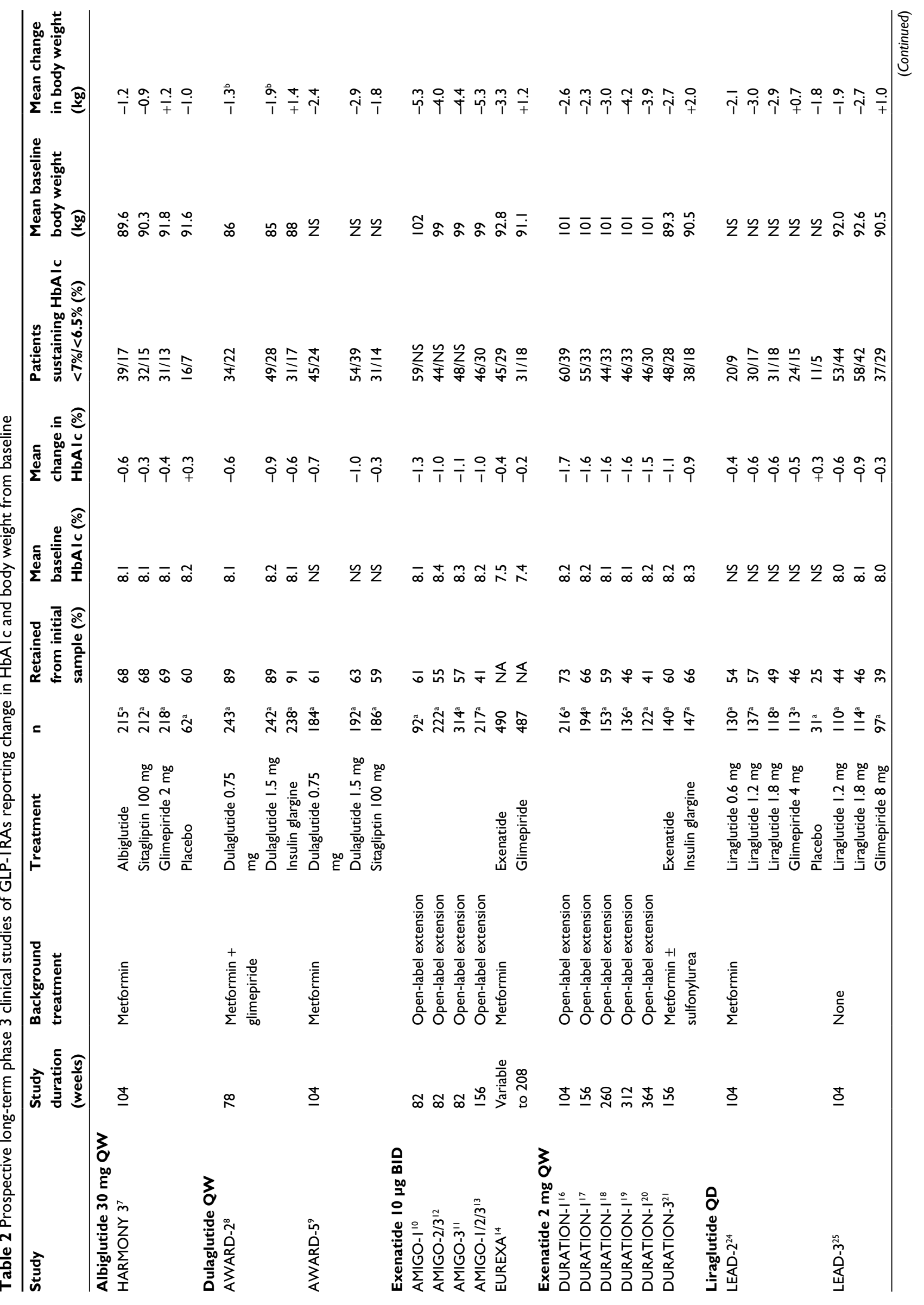




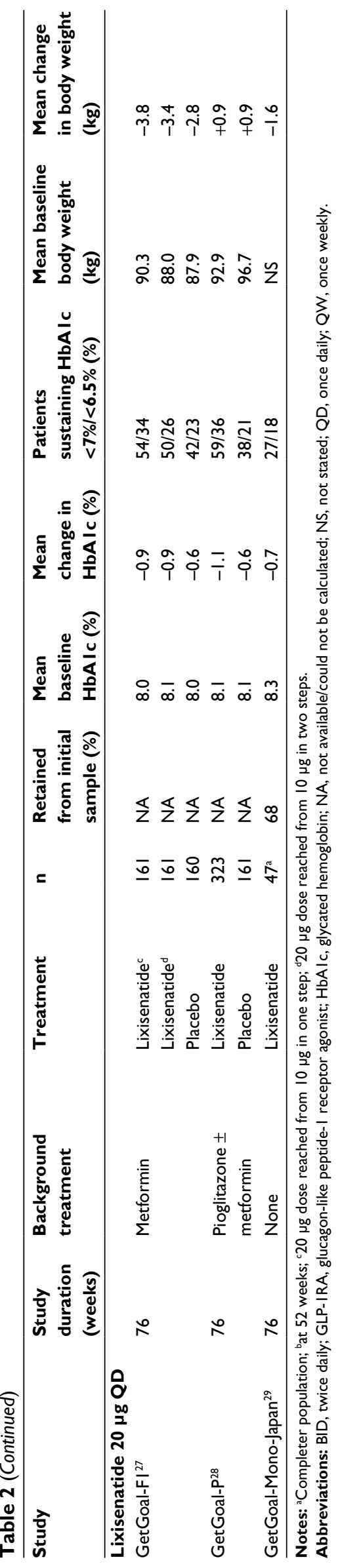

metformin and glimepiride. ${ }^{8} \mathrm{HbAlc}$ at 78 weeks and body weight at 52 weeks were reduced from baseline among patients receiving both doses. In AWARD-5, both the doses of dulaglutide were compared with sitagliptin over 104 weeks. ${ }^{9}$ Reductions in $\mathrm{HbAlc}$ and body weight were sustained over 2 years with both the doses. With dulaglutide $1.5 \mathrm{mg}$, reductions in $\mathrm{HbA} 1 \mathrm{c}$ and body weight were $-1.0 \%$ and $-2.9 \mathrm{~kg}$, respectively (Table 2).

Nausea, diarrhea, and vomiting were the most common adverse events over 104 weeks of treatment (Table 3). ${ }^{9}$ Among patients receiving dulaglutide, two severe cases of hypoglycemia occurred during AWARD $-2^{8}$ and no cases during AWARD-5. ${ }^{9}$ One case each of acute and chronic pancreatitis was diagnosed in the dulaglutide $1.5 \mathrm{mg}$ group in AWARD-2. ${ }^{8}$ In AWARD-5, a patient receiving dulaglutide $1.5 \mathrm{mg}$ died of stroke. ${ }^{9}$

\section{Exenatide twice daily (BID)}

Exenatide BID, the first GLP-1RA approved for clinical use, is administered before meals and has a half-life of $2.4 \mathrm{~h}$. Three 30-week pivotal trials evaluated two doses of exenatide BID (5 and $10 \mu \mathrm{g}$ ) in patients with inadequate glycemic control on metformin alone (AMIGO-1), SU alone (AMIGO-2), or SU and metformin combined (AMIGO-3). In open-label extension studies of the AMIGO trials, all the patients received the $10 \mu \mathrm{g}$ BID dose of exenatide and continued to receive prior background glucose-lowering medication (Table 2). In 52-week extensions of AMIGO- ${ }^{10}$ and AMIGO-3, ${ }^{11}$ patients completing 82 weeks of treatment maintained reductions in $\mathrm{HbA1c}$ and body weight from baseline (Table 2). Pooled data from AMIGO-2 and AMIGO-3 revealed a similar sustained decrease in $\mathrm{HbA} 1 \mathrm{c}$ and body weight after 82 weeks. ${ }^{12} \mathrm{~A}$ total of 217 patients from all the three AMIGO trials, who completed 156 weeks of exenatide BID treatment, maintained reductions from baseline of $-1.0 \%$ in $\mathrm{HbAl} \mathrm{c}$ and $-5.3 \mathrm{~kg}$ in body weight. ${ }^{13}$

EUREXA, a long-term randomized controlled trial, directly compared the treatment durability of exenatide BID with glimepiride after metformin failure in $\sim 1,000$ patients. ${ }^{14}$ Over 4 years, the treatment failure rate was $41 \%$ with exenatide BID and 54\% with glimepiride. At failure or completion of the study, $\mathrm{HbAlc}$ and body weight were reduced from baseline among patients receiving exenatide (Table 2).

Among patients with the longest exposure to exenatide in the AMIGO trials ( 3 years), the pattern of adverse events was consistent with long-term follow-up (Table 3). ${ }^{13}$ Less than $1 \%$ of withdrawals were attributed to hypoglycemia despite its high incidence (40\%), and the sole case of severe hypoglycemia occurred in a patient concurrently receiving metformin and an SU. ${ }^{13}$ 
Table 3 Key safety and tolerability findings in phase 3 clinical studies of GLP-IRAs

\begin{tabular}{|c|c|c|c|c|}
\hline Name & $\begin{array}{l}\text { Longest follow-up } \\
\text { (weeks) }\end{array}$ & Most common adverse events & $\begin{array}{l}\text { Incidence of } \\
\text { hypoglycemia }\end{array}$ & $\begin{array}{l}\text { Rate of withdrawal due } \\
\text { to adverse events }\end{array}$ \\
\hline $\begin{array}{l}\text { Albiglutide } 30 \mathrm{mg} \\
\mathrm{QW}^{7}\end{array}$ & 104 & $\begin{array}{l}\text { Upper respiratory tract infection, } \\
\text { 16.2\%; diarrhea, } 12.6 \% \text {; nausea, } \\
10.3 \% \text {; injection-site reactions, } 9.6 \%\end{array}$ & $\begin{array}{l}\text { Albiglutide, } 3.0 \% \text {; no severe } \\
\text { hypoglycemic events }\end{array}$ & Albiglutide, $6.6 \%$ \\
\hline Dulaglutide QW & 104 & $\begin{array}{l}\text { Nausea, } 15 \% \text {, } 17 \% \text {; diarrhea, } \\
\text { I2\%, } 16 \% \text {; vomiting, } 8 \%, 14 \% \\
\text { for dulaglutide } 0.75 \mathrm{mg}, 1.5 \mathrm{mg} \text {, } \\
\text { respectively } 9\end{array}$ & $\begin{array}{l}\text { Dulaglutide } 0.75 \mathrm{mg}, 8.6 \% \text {; } \\
1.5 \mathrm{mg}, 12.8 \% ; \text {; severe } \\
\text { hypoglycemia in two patients } \\
\text { on dulaglutide } 1.5 \mathrm{mg}^{8}\end{array}$ & $\begin{array}{l}\text { Dulaglutide } 0.75 \mathrm{mg}, 21 \% \text {; } \\
1.5 \mathrm{mg}, 21 \% 9\end{array}$ \\
\hline $\begin{array}{l}\text { Exenatide } 10 \mu \mathrm{g} \\
\mathrm{BID}^{13}\end{array}$ & 156 & $\begin{array}{l}\text { Nausea, } 59 \% \text {; hypoglycemia, } 40 \% \text {; } \\
\text { upper respiratory tract infection, } 36 \%\end{array}$ & $\begin{array}{l}\text { Exenatide, } 40 \% \text {; one severe } \\
\text { hypoglycemic event }\end{array}$ & Exenatide, II\% \\
\hline $\begin{array}{l}\text { Exenatide } 2 \mathrm{mg} \\
\mathrm{QW}^{19}\end{array}$ & 312 & $\begin{array}{l}\text { Upper respiratory tract infection, } \\
41.9 \% \text {; nasopharyngitis, } 28.3 \% \text {; } \\
\text { diarrhea, } 26.0 \% \text {; sinusitis, } 21.7 \%\end{array}$ & $\begin{array}{l}28.6 \% \text { with sulfonylurea; } \\
6.4 \% \text { with no sulfonylurea; no } \\
\text { severe hypoglycemic events }\end{array}$ & $\begin{array}{l}\text { Exenatide, } 6.2 \% \text { (between } \\
\text { weeks } 30-3 \mid 2 \text { ) }\end{array}$ \\
\hline Liraglutide QD & 104 & $\begin{array}{l}\text { Nausea, } 17.5 \%,{ }^{24} 29 \%{ }^{25} \text { for liraglutide } \\
\text { I.2 mg; } 21.5 \%,{ }^{24} 31 \%{ }^{25} \text { for liraglutide } \\
\text { I.8 mg; diarrhea, } 11.3 \%,{ }^{24} 18 \%{ }^{25} \text { for } \\
\text { I. } 2 \mathrm{mg} ; 16.5 \%,{ }^{24} 20 \%{ }^{25} \text { for } 1.8 \mathrm{mg}\end{array}$ & $\begin{array}{l}\text { Minor hypoglycemia with } \\
\text { liraglutide } 1.2 \mathrm{mg}: 4.2 \%,{ }^{24} \\
\text { I } 2 \% ;{ }^{25} \text { liraglutide } 1.8 \mathrm{mg}: \\
4.1 \%,{ }^{24} \text { 10\%, }{ }^{25} \text { two major } \\
\text { hypoglycemic events }\end{array}$ & $\begin{array}{l}\text { Liraglutide } \mathrm{I} .2 \mathrm{mg}, \mathrm{I} 2.9 \%,{ }^{24} \\
\mathrm{I} 2 \% ;^{25} \text { liraglutide } \mathrm{I} .8 \mathrm{mg} \\
\mathrm{I} 4.5 \%,{ }^{24} 9.3 \%{ }^{25}\end{array}$ \\
\hline $\begin{array}{l}\text { Lixisenatide } 20 \mu \mathrm{g} \\
\text { QD }\end{array}$ & 76 & $\begin{array}{l}\text { Nausea, } 26.0 \%-43.5 \% \text {; vomiting, } \\
7.2 \%-18.0 \% \text {; diarrhea, } 5.8 \%-14.9 \%^{27-29}\end{array}$ & $\begin{array}{l}\text { Symptomatic hypoglycemia: } \\
3.7 \%-7.5 \%,{ }^{27} 7.1 \%,{ }^{28} \\
7.2 \% ; ;^{29} \text { no cases of severe } \\
\text { hypoglycemia }\end{array}$ & $\begin{array}{l}\text { Lixisenatide, } 8.7 \%-11.8 \%,{ }^{27} \\
9.3 \%,{ }^{28} 14.5 \%{ }^{29}\end{array}$ \\
\hline
\end{tabular}

Abbreviations: BID, twice daily; GLP-IRA, glucagon-like peptide-I receptor agonist; QD, once daily; QW, once weekly.

\section{Exenatide QW}

The long-term effects of exenatide QW have been evaluated in the extension phases of the DURATION-1 and DURATION-3 studies (Table 2). The DURATION-1 study started with a 30-week randomized controlled period that compared exenatide QW with exenatide BID in patients who were drug-naïve or receiving background oral glucose-lowering agents. ${ }^{15}$ In open-label extension studies, patients previously receiving exenatide BID were switched to exenatide QW. After 2 years, ${ }^{16} 3$ years, ${ }^{17} 5$ years, ${ }^{18} 6$ years,,${ }^{19}$ and 7 years ${ }^{20}$ of follow-up, reductions in $\mathrm{HbA} 1 \mathrm{c}$ ( $-1.5 \%$ at 7 years) and body weight $(-3.9 \mathrm{~kg})$ were maintained compared with baseline (Table 2). These data represent the longest evaluation of a GLP-1RA published to date.

The long-term DURATION-1 study results are supported by randomized controlled 3-year extension data from the DURATION-3 trial of exenatide QW versus insulin glargine in patients uncontrolled on maximum-dose metformin with or without an SU (Table 2). ${ }^{21}$ At 3 years, study completers receiving exenatide QW achieved reductions of $-1.09 \%$ in $\mathrm{HbAlc}$ and $-2.69 \mathrm{~kg}$ in body weight relative to baseline (Table 2).

Respiratory tract infections were the most common adverse events reported in the 6-year DURATION-1 followup (Table 3). Exposure-adjusted event rates with exenatide QW decreased from 84.6 to 7.6 events/100 patient-years for nausea, whereas injection-site pruritus decreased from 51.0 to 1.6 events/100 patient-years during the initial 30-week and open-ended extension periods, respectively. ${ }^{19}$ No major hypoglycemic events were reported with exenatide QW. Most patients experiencing minor hypoglycemia were receiving a concomitant SU (28.6\% vs $6.4 \%$ non-SU). ${ }^{19}$ One case of pancreatitis in a patient receiving exenatide QW emerged during the 6-year follow-up period. ${ }^{19}$ Regarding other adverse events of interest, a pooled analysis of eight exenatide QW phase 3 trials (1,934 patients) found that renal failure-related adverse events occurred at a rate of 0.1 and thyroid neoplasms at a rate of 0.2 per 100 patient-years. There were no cases of thyroid cancer, C-cell carcinoma, or pancreatic cancer. ${ }^{22}$

\section{Liraglutide once daily (QD)}

Liraglutide, which is administered QD and has a half-life of $12.6 \mathrm{~h},{ }^{23}$ was the second GLP-1RA to market. Long-term data are presently available for two extension phases of the LEAD-2 and LEAD-3 trials (Table 2). In the 26-week LEAD-2 study, the glucose-lowering efficacy of liraglutide was compared with placebo and glimepiride, all on a background of metformin. After an open-label extension phase, the mean change in $\mathrm{HbAl} \mathrm{c}$ at 2 years was $-0.6 \%$ for both the 1.2 and $1.8 \mathrm{mg}$ doses of liraglutide, with a mean weight loss of -3.0 and $-2.9 \mathrm{~kg}$, respectively (Table 2). ${ }^{24}$ The LEAD-3 
trial evaluated liraglutide monotherapy over 104 weeks in comparison with glimepiride monotherapy. ${ }^{25} \mathrm{HbA} 1 \mathrm{c}$ reductions from baseline to 2 years were $-0.6 \%$ with liraglutide $1.2 \mathrm{mg}$ and $-0.9 \%$ with liraglutide $1.8 \mathrm{mg}$. Mean body weight reductions over 2 years were $-1.9 \mathrm{~kg}$ and $-2.7 \mathrm{~kg}$ for liraglutide 1.2 and $1.8 \mathrm{mg}$, respectively (Table 2$){ }^{25}$

One patient in each of the 2-year LEAD-2 and LEAD-3 studies experienced a major hypoglycemic event (Table 3). ${ }^{24,25}$ During the 30-week double-blind period of LEAD-2, two patients receiving liraglutide withdrew as a result of acute pancreatitis. ${ }^{24}$ However, no new cases were reported after 18 months of follow-up. During the extension phase of LEAD-3, one patient receiving liraglutide $1.8 \mathrm{mg}$ died, with an autopsy revealing signs of acute and chronic pancreatitis and cholelithiasis. ${ }^{25}$

\section{Lixisenatide QD}

To date, three studies have reported long-term efficacy outcomes for patients receiving lixisenatide, a medication administered QD with a half-life of 2-3 h (Table 2). ${ }^{26}$ During a 52-week extension of the GetGoal-F1 study in patients uncontrolled on metformin, lixisenatide maintained glycemic control at week 76. Mean $\mathrm{HbA1c}$ was reduced from baseline by $-0.9 \%$, and body weight decreased by $>3 \mathrm{~kg} .{ }^{27}$ In the GetGoal-P study, among patients receiving lixisenatide and also pioglitazone (with or without metformin), HbAlc was reduced from baseline by $-1.1 \%$ and body weight increased by $+0.9 \mathrm{~kg} .{ }^{28}$ In the third study, GetGoal-Mono-Japan, lixisenatide as monotherapy sustained glycemic control for up to 76 weeks (Table 2). ${ }^{29}$

After 76 weeks of lixisenatide therapy in the GetGoalF1, GetGoal-P, and GetGoal-Mono-Japan studies, gastrointestinal disorders were the most common adverse events (Table 3). ${ }^{27-29}$ There were no cases of severe hypoglycemia or pancreatitis. ${ }^{27-29}$

\section{Summary of findings}

Across all identified long-term studies for GLP-1RAs, the mean change in $\mathrm{HbA} 1 \mathrm{c}$ from baseline ranged from $-0.4 \%$ to $-1.7 \%$, with weight loss ranging from -0.9 to $-5.3 \mathrm{~kg}$. Although the degree of clinical benefit varied, all GLP-1RAs provided the means to achieve and maintain glycemic control in the long term among patients with T2D who continued therapy. GLP-1RAs may provide long-term benefits to patients, particularly those who desire or need to lose weight.

Although the tolerability profiles of the GLP-1RAs differ, nausea, diarrhea, upper respiratory tract infections, injection-site reactions, and hypoglycemia were reported across long-term GLP-1RA studies. However, the incidence of discontinuation related to adverse events was relatively low, at 4\%-21\%, with rates of withdrawals generally lower during continued treatment in extension trials. The tolerability profile of a GLP-1RA is an important consideration as it can be expected to influence both adherence and the overall duration of treatment. At present, the long-term evidence is insufficient to assert that GLP-1RAs have a benign side effect profile, particularly with respect to rare adverse events. However, it is reassuring that data from the DURATION-1 study showed no new safety signals emerging from 6 years of exposure to exenatide QW. In addition, diminished rates of gastrointestinal adverse events and injection-site reactions observed in this study suggest that extended use may ameliorate some adverse events. Indeed, an analysis that included data from the DURATION-1 study found that the incidence of nausea and vomiting, as assessed every 2 weeks, declined over time with continued exenatide therapy. ${ }^{30}$

Insulin is often recommended as add-on therapy to oral glucose-lowering agents, despite the associated risks of hypoglycemia and weight gain that have been shown to increase with increasing duration of insulin use. ${ }^{31-33}$ Importantly, a minimal propensity for hypoglycemia has been demonstrated in long-term studies of GLP-1RAs, along with clinically relevant decreases in body weight. The low rates of hypoglycemia observed over extended treatment durations with GLP-1RAs have important implications, particularly for patients considering an injectable agent for long-term use. The results of the head-to-head analyses of GLP-1RAs versus insulin suggest that a GLP-1RA is a better long-term treatment option, which may allow insulin to be used at a lower dose as add-on therapy if necessary.

Case reports of pancreatitis have emerged in studies of GLP-1RAs, prompting much debate in the literature concerning the potential for a causal relationship between the two. Although long-term studies of GLP-1RAs do not indicate an increased risk of pancreatitis, regulatory agencies continue to monitor signals for the GLP-1-based therapies with respect to pancreatic safety. ${ }^{34}$

There are important limitations to the studies reviewed which limit conclusions that can be drawn about relative efficacy and safety of the GLP-1RAs. Some of the long-term studies report open-label extensions or lacked a comparator arm, which limits conclusions that can be drawn about the agents' efficacy relative to other drug classes. None of the published long-term studies report a head-to-head comparison between two GLP-1RAs. Because of this, and differences between the studies in patient populations and methodologies, 
it is not possible to assess relative long-term efficacy or safety of the GLP-1RAs.

\section{Cardiovascular outcomes}

An important criterion for the use of glucose-lowering therapies among patients with T2D is the drugs' long-term effects on cardiovascular risk. ${ }^{35}$ Improved care of T2D over the last few decades, including tighter glucose, blood pressure, and lipid control, has reduced the incidences of myocardial infarction, stroke, and amputation among patients with poorly controlled T2D. ${ }^{36-40}$ However, the incidences of these outcomes remain high in a substantial patient population, ${ }^{41}$ representing a continued public health concern; hence, the cardiovascular safety of a number of GLP-1RAs is currently being studied.

The Liraglutide Effect and Action in Diabetes: Evaluation of Cardiovascular Outcome Results (LEADER) trial remains the largest and longest cardiovascular outcomes trial of a GLP-1RA completed to date. This phase 3, randomized, double-blind, placebo-controlled trial investigated the cardiovascular effect of liraglutide in 9,340 patients with T2D and high cardiovascular risk receiving standard T2D care. ${ }^{42}$ Patients were followed up for a minimum of 3.5 years and received liraglutide or placebo for a maximum of 5 years with a 30-day follow-up period. This study found that, over a median follow-up of 3.8 years, significantly fewer patients receiving liraglutide experienced the primary composite outcome of the first occurrence of death from cardiovascular causes, nonfatal myocardial infarction, or nonfatal stroke than patients receiving placebo $(13.0 \%$ vs $14.9 \%$ of patients; hazard ratio [HR], 0.87; 95\% confidence interval [CI], 0.78-0.97; $P=0.01$ for superiority). ${ }^{42}$ At 36 months, the treatment difference for change in $\mathrm{HbA} 1 \mathrm{c}$ was $-0.4 \%$ (95\% CI, $-0.5 \%$ to $-0.3 \%$ ) in favor of liraglutide, and body weight loss was $2.3 \mathrm{~kg}(95 \% \mathrm{CI}, 2.0-2.5 \mathrm{~kg})$ greater in the liraglutide group. ${ }^{42}$

The Evaluation of Lixisenatide in Acute Coronary Syndrome (ELIXA) trial investigated the cardiovascular effects of lixisenatide in 6,068 patients with T2D who had had myocardial infarction or who had been hospitalized for unstable angina in the last 180 days. ${ }^{43}$ This randomized, double-blind, placebo-controlled study followed up patients for a median of 25 months and demonstrated that there were no significant differences in cardiovascular events between lixisenatide and placebo, with the primary composite endpoint (cardiovascular death, myocardial infarction, stroke, hospitalization for unstable angina) occurring in $13.4 \%$ of patients receiving lixisenatide versus $13.2 \%$ of patients receiving placebo $(\mathrm{HR}, 1.02 ; 95 \% \mathrm{CI}, 0.89-1.17 ; P=0.81$ for superiority). ${ }^{43}$ Although these results are in contrast with the LEADER study, these discrepancies may be partly explained by substantial differences in the pharmacokinetics of the two GLP-1RA compounds: although liraglutide has a half-life of $\sim 13 \mathrm{~h}$, lixisenatide has a half-life of $\sim 3 \mathrm{~h}$. Taken together, results of the ELIXA and LEADER studies may indicate that drugs in the GLP-1RA class have a neutral or favorable effect on cardiovascular outcomes among patients with T2D.

Two clinical trials investigating the cardiovascular outcomes with albiglutide and exenatide QW are underway. Recruitment is ongoing for HARMONY Outcomes, a phase 3, randomized, double-blind, placebo-controlled trial that investigates the effect of albiglutide alone or in combination with standard glucose-lowering therapies on the risk of major cardiovascular events. ${ }^{44}$ Approximately 9,400 patients will be enrolled in the study if they are aged $\geq 40$ years and have T2D and established cardiovascular disease. The primary outcome will be the time to first occurrence of major cardiovascular events, and patients are expected to be followed up for 3-5 years. ${ }^{44}$

The long-term benefit of exenatide QW on cardiovascular outcomes is being investigated in the phase 3/4, double-blind, placebo-controlled EXenatide Study of Cardiovascular Event Lowering (EXSCEL) trial. ${ }^{45}$ Recruitment has now been completed, with an estimated 14,000 adult patients with T2D with or without cardiovascular disease enrolled worldwide. ${ }^{46}$ The primary endpoint is the incidence of a composite cardiovascular endpoint (cardiovascular death, nonfatal myocardial infarction, or nonfatal stroke), and the study will be terminated once this endpoint has been confirmed in 1,360 patients. ${ }^{45}$

Finally, long-term cardiovascular outcomes for patients with $\mathrm{T} 2 \mathrm{D}$ receiving dulaglutide are being investigated in the phase 3, double-blind, placebo-controlled Researching CV Events With a Weekly Incretin in Diabetes (REWIND) study. ${ }^{47}$ An estimated 9,622 patients aged $\geq 50$ years with vascular disease or cardiovascular risk factors will be followed for an average of 6.5 years. The primary outcome measure is time to first occurrence of cardiovascular death, nonfatal myocardial infarction, or nonfatal stroke (composite measure). The study is expected to be completed in 2018 .

\section{Conclusion}

A comprehensive body of long-term efficacy and safety data is emerging for the GLP-1RAs as a class, to rival that of SUs, TZDs, and insulin. Moreover, data on up to 6 years of exenatide QW use provide some assurance to patients and prescribers regarding long-term administration of these 
agents. Additional data from large ongoing cardiovascular outcome trials will provide important information on the long-term benefit-risk ratio of the GLP-1RA class.

\section{Acknowledgments}

Medical writing support was provided by Richard OgilvyStewart, PhD, of Mudskipper Business Limited and funded by AstraZeneca, United Kingdom. Editorial assistance was also provided by Lisa Baker of inScience Communications, Springer Healthcare (New York, NY, USA), funded by AstraZeneca.

\section{Disclosure}

HC has received speaker fees from Abbott, AstraZeneca, Eli Lilly, Merck Sharp \& Dohme, Novo Nordisk, Pfizer, and Sanofi and has also been on advisory boards for AstraZeneca, Eli Lilly, and Novo Nordisk. RN has received speaker fees from AstraZeneca, Boehringer Ingelheim, Eli Lilly, Janssen, Merck Sharp \& Dohme, Novo Nordisk, and Sanofi. CR has received speaker and advisory board member fees from Abbott, AstraZeneca, Boehringer Ingelheim, Eli Lilly, Janssen, Merck Sharp \& Dohme, Novo Nordisk, and Sanofi. RJ was a Consultant Pharmaceutical Physician contracted with AstraZeneca during the development of the manuscript. The authors report no other conflicts of interest in this work.

\section{References}

1. Garber AJ, Abrahamson MJ, Barzilay JI, et al. Consensus statement by the American Association of Clinical Endocrinologists and American College of Endocrinology on the comprehensive type 2 diabetes management algorithm-2016 executive summary. Endocr Pract. 2016;22(1):84-113.

2. Inzucchi SE, Bergenstal RM, Buse JB, et al. Management of hyperglycemia in type 2 diabetes, 2015: a patient-centered approach: update to a position statement of the American Diabetes Association and the European Association for the Study of Diabetes. Diabetes Care. 2015; 38(1):140-149.

3. Kahn SE, Haffner SM, Heise MA, et al. Glycemic durability of rosiglitazone, metformin, or glyburide monotherapy. N Engl J Med. 2006; 355(23):2427-2443.

4. Cefalu WT, Buse JB, Del Prato S, et al. Beyond metformin: safety considerations in the decision-making process for selecting a second medication for type 2 diabetes management: reflections from a Diabetes Care editors' expert forum. Diabetes Care. 2014;37(9):2647-2659.

5. Tahrani AA, Barnett AH, Bailey CJ. Pharmacology and therapeutic implications of current drugs for type 2 diabetes mellitus. Nat Rev Endocrinol. 2016;12(10):566-592.

6. Drucker DJ. The biology of incretin hormones. Cell Metab. 2006; 3(3):153-165.

7. Ahren B, Johnson SL, Stewart M, et al. HARMONY 3: 104-week randomized, double-blind, placebo- and active-controlled trial assessing the efficacy and safety of albiglutide compared with placebo, sitagliptin, and glimepiride in patients with type 2 diabetes taking metformin. Diabetes Care. 2014;37(8):2141-2148

8. Giorgino F, Benroubi M, Sun JH, Zimmermann AG, Pechtner V. Efficacy and safety of once-weekly dulaglutide versus insulin glargine in patients with type 2 diabetes on metformin and glimepiride (AWARD-2). Diabetes Care. 2015;38(12):2241-2249.
9. Weinstock RS, Guerci B, Umpierrez G, Nauck MA, Skrivanek Z, Milicevic Z. Safety and efficacy of once-weekly dulaglutide versus sitagliptin after 2 years in metformin-treated patients with type 2 diabetes (AWARD-5): a randomized, phase III study. Diabetes Obes Metab. 2015;17(9):849-858.

10. Ratner RE, Maggs D, Nielsen LL, et al. Long-term effects of exenatide therapy over 82 weeks on glycaemic control and weight in over-weight metformin-treated patients with type 2 diabetes mellitus. Diabetes Obes Metab. 2006;8(4):419-428.

11. Blonde L, Klein EJ, Han J, et al. Interim analysis of the effects of exenatide treatment on $\mathrm{A} 1 \mathrm{C}$, weight and cardiovascular risk factors over 82 weeks in 314 overweight patients with type 2 diabetes. Diabetes Obes Metab. 2006;8(4):436-447.

12. Riddle MC, Henry RR, Poon TH, et al. Exenatide elicits sustained glycaemic control and progressive reduction of body weight in patients with type 2 diabetes inadequately controlled by sulphonylureas with or without metformin. Diabetes Metab Res Rev. 2006;22(6):483-491.

13. Klonoff DC, Buse JB, Nielsen LL, et al. Exenatide effects on diabetes, obesity, cardiovascular risk factors and hepatic biomarkers in patients with type 2 diabetes treated for at least 3 years. Curr Med Res Opin. 2008;24(1):275-286.

14. Gallwitz B, Guzman J, Dotta F, et al. Exenatide twice daily versus glimepiride for prevention of glycaemic deterioration in patients with type 2 diabetes with metformin failure (EUREXA): an open-label, randomised controlled trial. Lancet. 2012;379(9833):2270-2278.

15. Drucker DJ, Buse JB, Taylor K, et al. Exenatide once weekly versus twice daily for the treatment of type 2 diabetes: a randomised, openlabel, non-inferiority study. Lancet. 2008;372(9645):1240-1250.

16. Taylor K, Gurney K, Han J, Pencek R, Walsh B, Trautmann M. Exenatide once weekly treatment maintained improvements in glycemic control and weight loss over 2 years. BMC Endocr Disord. 2011;11:9.

17. Macconell L, Pencek R, Li Y, Maggs D, Porter L. Exenatide once weekly: sustained improvement in glycemic control and cardiometabolic measures through 3 years. Diabetes Metab Syndr Obes. 2013;6:31-41.

18. Wysham CH, MacConell LA, Maggs DG, Zhou M, Griffin PS, Trautmann ME. Five-year efficacy and safety data of exenatide once weekly: long-term results from the DURATION-1 randomized clinical trial. Mayo Clin Proc. 2015;90(3):356-365.

19. Henry RR, Klein EJ, Han J, Iqbal N. Efficacy and tolerability of exenatide once weekly over 6 years in patients with type 2 diabetes: an uncontrolled open-label extension of the DURATION-1 study. Diabetes Technol Ther. 2016;18(11):677-686.

20. Wysham CH, Philis-Tsimikas A, Klein EJ, et al. DURATION-1 extension in patients with T2D: efficacy and tolerability of exenatide once weekly (QW) over 7 years (abstract 1041-P). Diabetes. 2016;65(Suppl 1): A221-A360.

21. Diamant M, Van Gaal L, Guerci B, et al. Exenatide once weekly versus insulin glargine for type 2 diabetes (DURATION-3): 3-year results of an open-label randomised trial. Lancet Diabetes Endocrinol. 2014; 2(6):464-473.

22. MacConell L, Gurney K, Malloy J, Zhou M, Kolterman O. Safety and tolerability of exenatide once weekly in patients with type 2 diabetes: an integrated analysis of 4,328 patients. Diabetes Metab Syndr Obes. 2015;8:241-253.

23. Agerso H, Jensen LB, Elbrond B, Rolan P, Zdravkovic M. The pharmacokinetics, pharmacodynamics, safety and tolerability of NN2211, a new long-acting GLP-1 derivative, in healthy men. Diabetologia. 2002; 45(2):195-202.

24. Nauck M, Frid A, Hermansen K, et al. Long-term efficacy and safety comparison of liraglutide, glimepiride and placebo, all in combination with metformin in type 2 diabetes: 2-year results from the LEAD-2 study. Diabetes Obes Metab. 2013;15(3):204-212.

25. Garber A, Henry RR, Ratner R, Hale P, Chang CT, Bode B. Liraglutide, a once-daily human glucagon-like peptide 1 analogue, provides sustained improvements in glycaemic control and weight for 2 years as monotherapy compared with glimepiride in patients with type 2 diabetes. Diabetes Obes Metab. 2011;13(4):348-356. 
26. Petersen AB, Christensen M. Clinical potential of lixisenatide once daily treatment for type 2 diabetes mellitus. Diabetes Metab Syndr Obes. 2013;6:217-231.

27. Bolli GB, Munteanu M, Dotsenko S, et al. Efficacy and safety of lixisenatide once daily vs. placebo in people with type 2 diabetes insufficiently controlled on metformin (GetGoal-F1). Diabet Med. 2014;31(2): 176-184.

28. Pinget M, Goldenberg R, Niemoeller E, Muehlen-Bartmer I, Guo H, Aronson R. Efficacy and safety of lixisenatide once daily versus placebo in type 2 diabetes insufficiently controlled on pioglitazone (GetGoal-P). Diabetes Obes Metab. 2013;15(11):1000-1007.

29. Seino Y, Yabe D, Takami A, Niemoeller E, Takagi H. Long-term safety of once-daily lixisenatide in Japanese patients with type 2 diabetes mellitus: GetGoal-Mono-Japan. J Diabetes Complications. 2015;29(8):1304-1309.

30. Ridge T, Moretto T, MacConell L, et al. Comparison of safety and tolerability with continuous (exenatide once weekly) or intermittent (exenatide twice daily) GLP-1 receptor agonism in patients with type 2 diabetes. Diabetes Obes Metab. 2012;14(12):1097-1103.

31. Gerstein HC, Miller ME, Byington RP, et al. Effects of intensive glucose lowering in type 2 diabetes. $N$ Engl J Med. 2008;358(24):2545-2559.

32. Henderson JN, Allen KV, Deary IJ, Frier BM. Hypoglycaemia in insulintreated type 2 diabetes: frequency, symptoms and impaired awareness. Diabet Med. 2003;20(12):1016-1021.

33. UK Hypoglycaemia Study Group. Risk of hypoglycaemia in types 1 and 2 diabetes: effects of treatment modalities and their duration. Diabetologia. 2007;50(6):1140-1147.

34. Egan AG, Blind E, Dunder K, et al. Pancreatic safety of incretin-based drugs-FDA and EMA assessment. NEngl J Med. 2014;370(9):794-797.

35. US Food and Drug Administration. Guidance for industry: diabetes mellitus - evaluating cardiovascular risk in new antidiabetic therapies to treat type 2 diabetes. Available from: http://www.fda.gov/downloads/drugs/guidancecomplianceregulatoryinformation/guidances/ ucm071627.pdf. Accessed June 30, 2016.

36. The Diabetes Control and Complications Trial Research Group. The effect of intensive treatment of diabetes on the development and progression of long-term complications in insulin-dependent diabetes mellitus. N Engl J Med. 1993;329(14):977-986.
37. The Diabetes Control and Complications Trial (DCCT) Research Group. Effect of intensive diabetes management on macrovascular events and risk factors in the Diabetes Control and Complications Trial. Am J Cardiol. 1995;75(14):894-903.

38. UK Prospective Diabetes Study Group. Tight blood pressure control and risk of macrovascular and microvascular complications in type 2 diabetes: UKPDS 38. BMJ. 1998;317(7160):703-713.

39. UK Prospective Diabetes Study (UKPDS) Group. Intensive bloodglucose control with sulphonylureas or insulin compared with conventional treatment and risk of complications in patients with type 2 diabetes (UKPDS 33). Lancet. 1998;352(9131):837-853.

40. Gaede P, Vedel P, Larsen N, Jensen GV, Parving HH, Pedersen O. Multifactorial intervention and cardiovascular disease in patients with type 2 diabetes. $N$ Engl J Med. 2003;348(5):383-393.

41. Gregg EW, LiY, Wang J, et al. Changes in diabetes-related complications in the United States, 1990-2010. N Engl JMed. 2014;370(16):1514-1523.

42. Marso SP, Daniels GH, Brown-Frandsen K, et al. Liraglutide and cardiovascular outcomes in type 2 diabetes. NEngl J Med. 2016;375(4):311-322.

43. Pfeffer MA, Claggett B, Diaz R, et al. Lixisenatide in patients with type 2 diabetes and acute coronary syndrome. N Engl J Med. 2015;373(23): 2247-2257.

44. ClinicalTrials.gov. Effect of albiglutide, when added to standard blood glucose lowering therapies, on major cardiovascular events in subjects with type 2 diabetes mellitus - NCT02465515. Available from: https:// clinicaltrials.gov/ct2/show/NCT02465515?term=NCT02465515\&r ank=1. Accessed August 18, 2016.

45. Holman RR, Bethel MA, George J, et al. Rationale and design of the EXenatide Study of Cardiovascular Event Lowering (EXSCEL) trial. Am Heart J. 2016;174:103-110.

46. ClinicalTrials.gov. EXenatide Study of Cardiovascular Event Lowering trial (EXSCEL): a trial to evaluate cardiovascular outcomes after treatment with exenatide once weekly in patients with type 2 diabetes mellitus NCT01144338. Available from: https://clinicaltrials.gov/ct2/show/NCT 01144338?term=NCT01144338\&rank=1. Accessed August 18, 2016.

47. ClinicalTrials.gov. Researching Cardiovascular Events With a Weekly Incretin in Diabetes (REWIND) - NCT01394952. Available from: https:// clinicaltrials.gov/ct2/show/NCT01394952. Accessed January 30, 2017.

Diabetes, Metabolic Syndrome and Obesity: Targets and Therapy

Dovepress

\section{Publish your work in this journal}

Diabetes, Metabolic Syndrome and Obesity: Targets and Therapy is an international, peer-reviewed open-access journal committed to the rapid publication of the latest laboratory and clinical findings in the fields of diabetes, metabolic syndrome and obesity research Original research, review, case reports, hypothesis formation, expert opinion and commentaries are all considered for publication. The manuscript management system is completely online and includes a very quick and fair peer-review system, which is all easy to use. Visit http://www.dovepress.com/testimonials.php to read real quotes from published authors.

Submit your manuscript here: https://www.dovepress.com/diabetes-metabolic-syndrome-and-obesity-targets-and-therapy-journal 